DOI: https://doi.org/10.24867/07AM05Trifunovic

\title{
UTICAJ OBLIKA RAZVODNIKA NA BRZINU LIVA PRI GRAVITACIONOM LIVENJU ALUMINIJUMA
}

\section{THE INFLUENCE OF THE RUNNER SHAPE ON MELT VELOCITY IN ALUMINUM GRAVITY CASTING}

\author{
Slaviša Trifunović, Lazar Kovačević, Fakultet tehničkih nauka, Novi Sad
}

\begin{abstract}
Oblast - PROIZVODNO MAŠINSTVO
Kratak sadržaj - Kvalitet aluminijumskih odlivaka $u$ velikoj meri zavisi od oblika ulivnog sistema koji treba da obezbedi kontrolisano ulivanje brzinom nižom od kritične. $U$ radu su prezentovani rezultati merenja brzine rastopljenog aluminijuma na izlazu iz razvodnika pomoću metode praćenja trajektorije pri slobodnom isticanju iz horizontalnog kanala. Istraživanja su sprovedena za različite oblike razvodnika.
\end{abstract}

Ključne reči: Popunjavanje kalupa, Ulivni sistem, brzina rastopa

\begin{abstract}
Quality of aluminum alloy castings rely on the gating system design and its ability to provide controlled filling with lower than critical velocities. Runner exit velocities for several runner shapes were calculated by the trajectory tracking method by ejecting the melt through the open horizontal runner.
\end{abstract}

Keywords: Mold filling, gating system, metal velocity

\section{UVOD}

Prilikom ulivanja rastopljenog metala dolazi do zahvatanja gasova i oksida, nemetalnih uključaka i drugih nečistoća. Iz tog razloga može se smatrati de je većina rastopljenih metala puna unutrašnjih grešaka koje značajno smanjuju njegove mehaničke osobine [1]. Iako veliki uticaj na kvalitet odlivka ima početno stanje rastopa u peći, odnosno ulivnoj kašici, površinska turbulencija unutar ulivnog sistema takođe ima značajnu ulogu. Da bi se smanjio procenat grešaka i dobio kvalitetan odlivak neophodno je projektovati optimalan ulivni sistem koji ima za zadatak obezbeđivanje prenosa čistog rastopa iz lonca u kalupnu šupljinu, a da nakon toga ne dođe do reoksidacije ili povećavanja sadržaja gasova. Osnovni zadaci ulivnog sistema su [2,3]:

- kontrola brzine ulivanja u kalupnu šupljinu kako ne bi došlo do hladnih zavara i nedolivenosti u odlivku

- popunjavanje kalupne šupljine tako da se ne pojavi zahvatanje gasova, šljake i oksida i njihov ulazak u kalupnu šupljinu;

- sprečavanje erozije kalupa;

- minimalan utrošak materijala;

- lako odvajanje od odlivka pri čišćenju;

\section{NAPOMENA:}

Ovaj rad proistekao je iz master rada čiji mentor je bio doc. dr Lazar Kovačević
- rastopljen materijal je potrebno uliti u kalupnu šupljinu tako da obezbedi usmereno očvršćavanje odlivka ka hraniocu. Rastop koji poslednji ulazi u kalup ima najveću temperaturu te je iz tog razloga neophodno pozicionirati ulivni sistem na mestu gde se očekuje zadnje očvršćavanje odlivka.

- sprečavanje deformacija odlivka. Ovaj problem je posebno izražen kod tankozidih odlivaka gde nepravilan raspored toplote dovodi do nepoželjnog načina očvršćavanja i vitoperenja odlivka, dok skupljanje ulivnika tokom hlađenja može prouzrokovati pojavu vrućih prslina u odlivku.

Tokom vremena, razvijen je veliki broj oblika ulivnih sistema koji nude mogućnost ispunjavanja navedenih zadataka. Svaki od njih karakterišu četiri osnovna elementa [3]:

- ulivna čaša,

- sprovodnik,

- razvodnik,

- ulivnik, ulivni kanal.

Pored njih, u cilju povećanja kvaliteta konačnog odlivka, mogu se projektovati i neki dodatni elementi kao što su prigušnice, kolektori, filteri, hvatači šljake, produžeci razvodnika i sl. Konačan oblik ulivnog sistema zavisi od više faktora, od kojih su za najznačajniji [4]:

- primenjena tehnologija (postupak) livenja,

- geometrija odlivka,

- vrsta materijala.

Novija istraživanja pokazuju da je za dobijanje dobrih mehaničkih osobina aluminijumskih odlivaka, neophodno smanjiti brzinu rastopa u ulivnom kanalu na oko $0,5 \mathrm{~m} / \mathrm{s}$ [5]. Ovaj uslov je veoma teško zadovoljiti jer se navedena kritična brzina dostiže već nakon pada rastopa sa visine od oko $13 \mathrm{~mm}$ [1]. Skoro svi odlivci koji se industrijski proizvode su značajno većih dimenzija i zahtevaju upotrebu sprovodnika koji su viši za barem jedan red veličina, a u velikom broju slučajeva i za dva reda veličina. Stoga se pri projektovanju ulivnog sistema velika pažnja mora posvetiti načinima za usporavanje liva pre izlaska iz ulivnog kanala. Kako bi se ulivni sistem mogao pravilno dimenzionisati tako da omogući ispunjavanje navedenog uslova, neophodno je što preciznije poznavanje gubitaka koji se javljaju u različitim elementima ulivnog sistema. Predstavljeni rezultati predstavljaju deo šireg istraživanja sa ciljem da se oni precizno definišu. 


\section{METODOLOGIJA}

Osnovni ispitivani ulivni sistem je prikazan na slici 1 . Proračun je izveden uzimajući u obzir trenutno dostupne tablice koje za jednostavne ulivne sisteme definišu koeficijent isticanja od 0,8 [6].

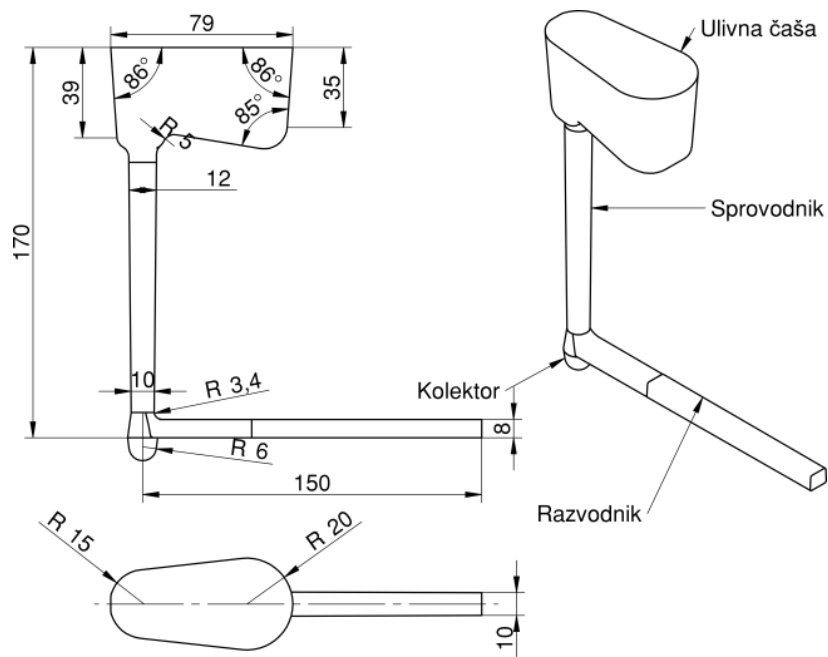

Slika 1. Izgled osnovnog ulivnog sistema (ravan normalni)

Zadržavajući isti oblik ulivne čaše, sprovodnika i osnove sprovodnika, brzina isticanja rastopa je merena za još tri ulivna sistema koji se od osnovnog (nazvanog ravan normalni) razlikuju u sledećem:

- razvodnik je sa $8 \mathrm{~mm}$ povišen na $16 \mathrm{~mm}$ - u daljem tekstu nazvan ravan povišen

- razvodnik je urađen sa dodanim krivinama kako bi se usporio rastop - u dalje tekstu nazvan krivudavi normalan, slika 2.

- razvodnik je urađen sa dodatnim krivinama kao i krivudavi normalan, ali uz dodatno povišenje razvodnika sa $8 \mathrm{~mm}$ na $16 \mathrm{~mm}$.

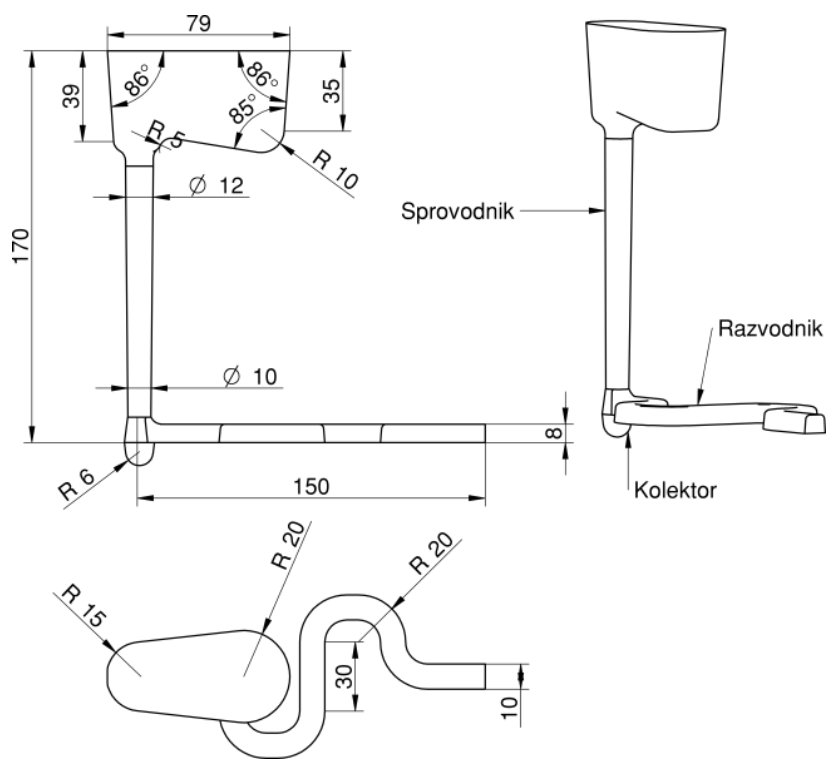

Slika 2. Izgled ulivnog sistema sa dodatim krivinama $u$ razvodniku (krivudavi normalni)

Za potrebe kalupovanja segmenti modela ulivnog sistema su izrađeni deponovanjem istopljenog filamenta. Ulivni sistem je izrađen modularno kako bi mogao da se nesmetano vadi iz kalupa, a pojedini elementi koriste više puta u različitim varijacijama. Kalupnice u kojima su izrađivani kalupi su napravljene sa šarkama tako da se mogu otvoriti i osloboditi kalup. Na taj način omogućeno je nesmetano isticanje liva iz kalupa.

Klupi su izrađeni od smeše gipsa, peska i vode $u$ zapreminskom odnosu 7:7:4,5 čime je omogućeno višestruko ulivanje u isti kalup. Dno kalupa u koji se ulivao rastop se nalazilo na visini od $317 \mathrm{~mm}$ od poda. Pomoću termopara koji je postavljen u ulivnu čašu praćena je temperatura rastopa kako bi se isključio uticaj promene temperature na viskoznost liva. Zidovi kalupnih šupljina su postavljani paralelno $u$ odnosu na papir na kome je odštampana mreža dimenzija 10 x $10 \mathrm{~mm}$. Podeona ravan kalupa postavljana je u horizontalan položaj pomoću libele, slika 3 .

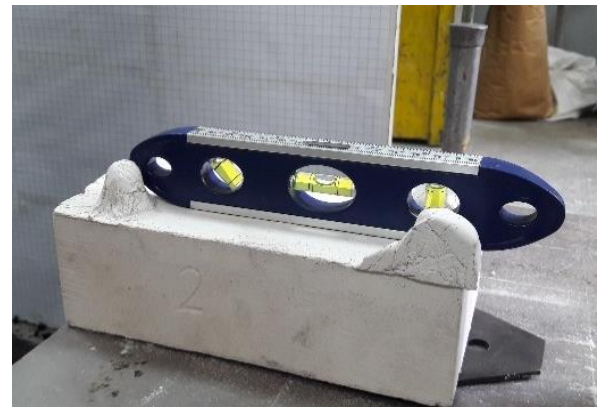

Slika 3. Dovođenje podeone ravni u horizontalni položaj

Svako ulivanje je snimano kamerom postavljenom upravno u odnosu na pravac isticanja. Objektiv kamere je podešavan tako da se njegova osa poklapa sa mestom isticanja rastopa. Snimci isticanja su obrađivani u programu „Media player classic home cinema“ gde su isecane slike za potrebe određivanja brzina isticanja u pravilnim vremenskim intervalima u odnosu na prvi frejm na kojem se primećuje liv. Ovako dobijene slike su naknadno obrađivane u programskom paketu „GNU-Image Manipulation Program“" gde je vršena njihova rotacija kako bi se uklonila eventualna greška položaja objektiva kamere. Obrađene slike su unošene u program „Microsoft Excel" u kojima je vršena procena brzine isticanja, slika 3. Procena je vršena poređenjem trajektorije tečnog rastopa sa idealnom trajektorijom horizontalnog hica koja je dobijena pomoću izraza (1):

$$
y_{i}=-\frac{g \cdot x_{i}^{2}}{2 v^{2}}, \quad i=1 \ldots 240
$$

gde su: $x_{i}$ i $y_{i}$ dekartove koordinate posmatrane tačke trajektorije $\left(x_{i}=0,001 \cdot i[m]\right), v$ - početna brzina isticanja liva, $g$ - gravitaciono ubrzanje.

Vrednost početne brzine isticanja je varirana sve dok se nije postiglo poklapanje teorijske trajektorije horizontalnog hica sa oblikom struje tečnog metala na slici 4 . Minimalna i maksimalna brzina isticanja određivane su iz razloga što je otežano pronalaženje linije srednje brzine, te je ovom metodom pouzdanije iznalaženje srednje brzine isticanja. Ova procedura je ponavljana za svaki razmatrani vremenski trenutak i za svako ulivanje.

Kako bi se imao uvid u ponovljivost rezultata planirano je vršenje tri ponavljanja za svaku varijaciju oblika razvodnika. 


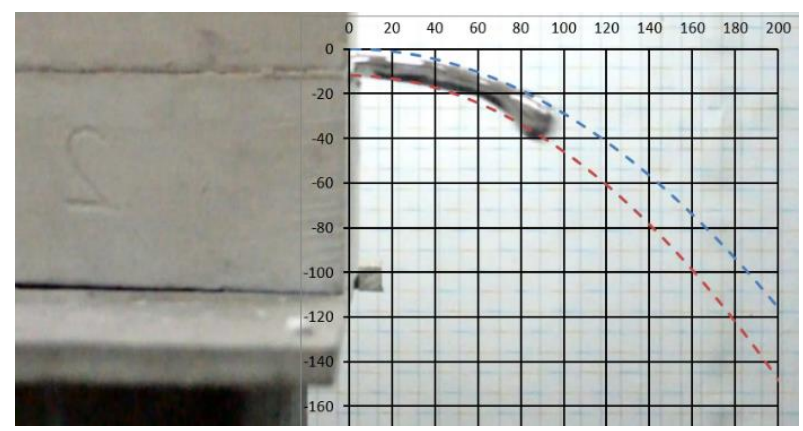

Slika 4. Primer određivanja maksimalne i minimalne brzine isticanja u programu Microsoft Excel

\section{REZULTATI I DISKUSIJA}

Termoparovi postavljeni u ulivnu čašu pokazali su zadovoljavajuću ponovljivost temperature ulivanja. Prosečna temperatura ulivanja je iznosila $672 \pm 15^{\circ} \mathrm{C}$. Prilikom izvođenja eksperimenta, usled aksijalnog skupljanja odlivka dobijenih krivudavim razvodnicima dolazilo je do oštećenja kalupa. Na temperaturama ulivanja aluminijuma dolazi do slabljenja gipsanog veziva i prilikom vađenja odlivaka iz kalupa dolazilo je do njegovog oštećenja, zbog čega je postajao neupotrebljiv za dalje eksperimente. Broj izvedenih ulivanja za različite oblike razvodnika dat je u tabeli 1 .

Tabela 1. Izvedeni broj ulivanja za svaki oblik razvodnika

\begin{tabular}{|l|c|}
\hline \multicolumn{1}{|c|}{ Oblik razvodnika } & Broj ulivanja \\
\hline Ravan normalan $(\mathrm{RN})$ & 3 \\
\hline Ravan povišen $(\mathrm{RP})$ & 3 \\
\hline Krivudav normalan $(\mathrm{KN})$ & 2 \\
\hline Krivudav povišen $(\mathrm{KP})$ & 1 \\
\hline
\end{tabular}

Tipičan oblik promene brzine isticanja liva iz kalupa prikazan je na slikama 5 i 6 .

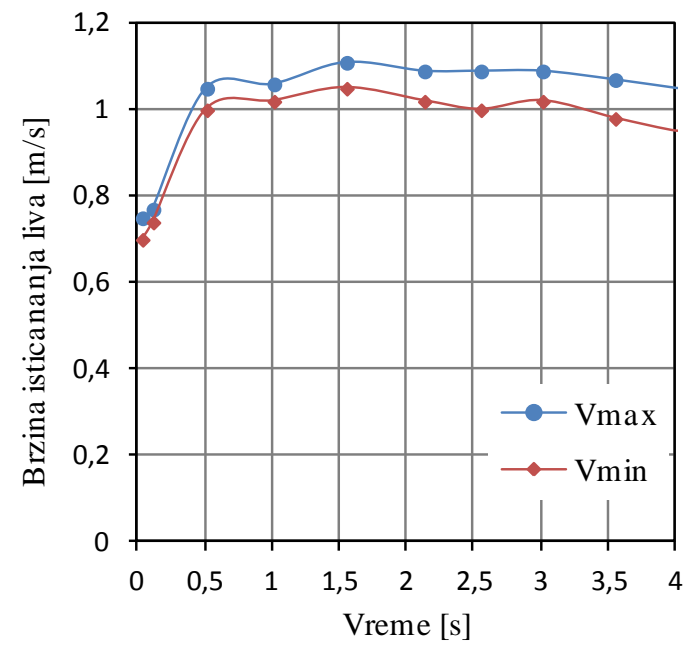

Slika 5. Primer dijagrama brzine isticanja za ravan normalan razvodnik

U prvih pola sekunde brzina liva raste dok se ne uspostavi regularan režim strujanja metala. Ovaj rast brzine je najverovatnije povezan sa procesom popunjavanja ulivne čaše i potpunim ispunjavanjem ulivnog sistema tečnim livom. Nakon tog početnog vremena, procenjene brzine isticanja su relativno ujednačene, ali ne i potpuno konstantne. Pretpostavlja se da je ovo oscilovanje posledica blage varijacije u visini liva u ulivnoj čaši koje se pod dejstvom gravitacije pretvara u varijaciju brzine isticanja. Iako se pri ulivanju rastopa vodilo računa o ovoj pojavi, činjenica da je ulivanje vršeno ručno onemogućila je apsolutnu kontrolu visine. Za dobijanje preciznijih rezultata merenja u budućim istraživanjima moguće je izmeniti postojeću geometriju ulivne čaše dodavanjem prelivnog kanala, poput one korišćene u referenci [7].

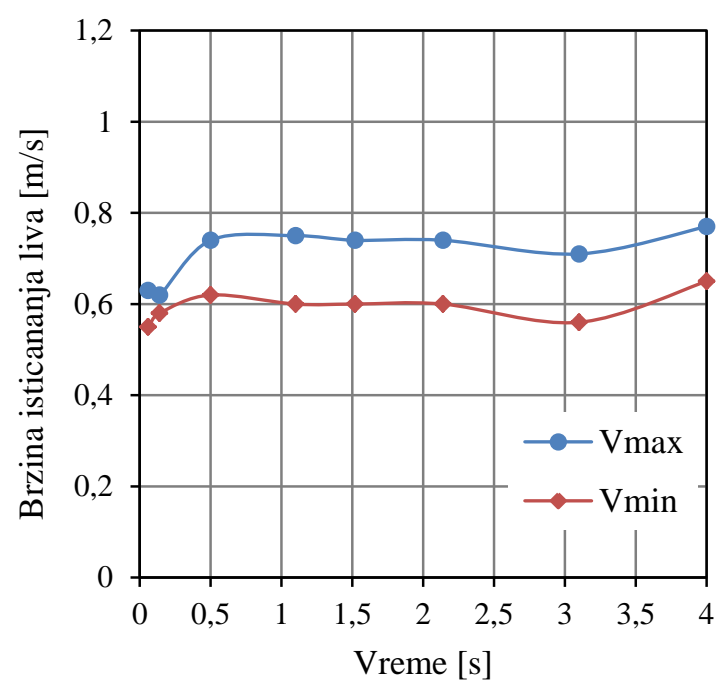

Slika 6. Primer dijagrama brzine isticanja za krivudav normalan razvodnik

Analizom dijagrama prikazanih na slikama 5 i 6 uočljivo je da se za istu veličinu poprečnog preseka brzine isticanja liva smanjuju dodavanjem krivina u razvodnik. Ovakav rezultat i jeste bio očekivan s obzirom da svaka promena pravca tečenja struje rastopa dovodi do određenih energetskih gubitaka. Međutim, postavlja se pitanje da li su navedene razlike statistički značajne i da li je razvijena eksperimentalna postavka dovoljna da ovu razliku i dokaže. Stoga su za svako ulivanje za određeni oblik hranioca objedinjene sve izmerene brzine, (uključujući maksimalne i minimalne) i za njih je određena srednja vrednost, standardna devijacija i 95\% interval poverenja srednje vrednosti. Kako bi se izbegla greška početnog popunjavanja ulivnog sistema, u razmatranje su uzete samo brzine nakon $0,5 \mathrm{~s}$ od početka isticanja. Dobijeni rezultati prikazani su na slici 7. Može se uočiti da je interval poverenja relativno uzak uzimajući u obzir razlike u izmerenim brzinama isticanja. Stoga se može konstatovati da je razvijena eksperimentalna metodologija adekvatna za datu namenu.

Analizom rezultata prikazanih na slici 7 može se uočiti da su najviše brzine isticanja povezane sa ravnim normalnim razvodnikom, dok je najniža brzina isticanja ostvarena primenom krivudavog povišenog razvodnika. Krivudavi razvodnici su bili u stanju da snize brzine strujanja liva $u$ znatno većoj meri nego što su to ostvarili ravni razvodnici. Prosečna brzina isticanja iz ravnog normalnog razvodnika iznosila je $0,98 \mathrm{~m} / \mathrm{s}$, što je niže od očekivane brzine koja za koeficijent isticanja od 0,8 iznosi 1,38 m/s. Istovremeno, prosečna brzina isticanja iz ravnog povišenog razvodnika od $0,75 \mathrm{~m} / \mathrm{s}$ ukazuje da se $\mathrm{u}$ tom slučaju koeficijent isticanja može proceniti na oko 0,55 . 


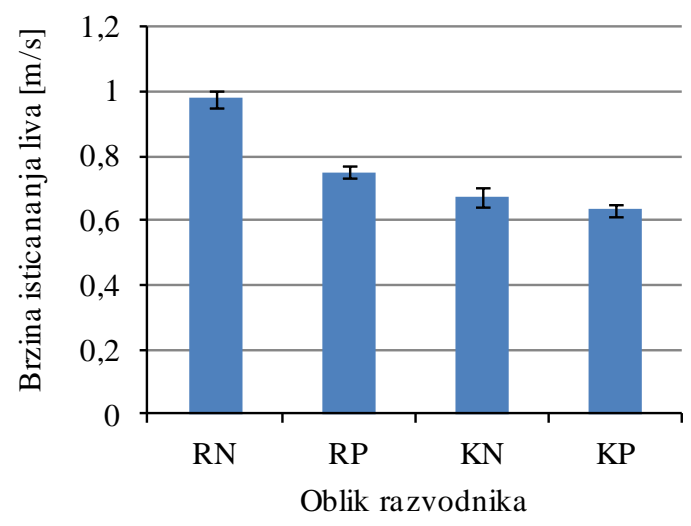

Slika 7. Srednje vrednosti brzine isticanja za svaki oblik razvodnika. Trake sa greškama pokazuju 95\% interval poverenja

Dobijena razlika se može objasniti na sledeći način. Realni koeficijent isticanja koji ukazuje na gubitke ravnog ulivnog sistema iznosi oko 0,55. Međutim, kako bi ulivni sistem bio u stanju da iskoristi sve prisutne energetske gubitke, neophodno je da nakon svakog usporavanja liva dođe do proširenja poprečnog preseka posmatranog elementa. U suprotnom, ulivni sistem ima ulogu mlaznice koja efektivno povećava brzinu strujanja liva [1,5,7]. Ravni povišen ulivni sistem je bio predimenzionisan, nije bilo efekta mlaznice i svi energetski gubici unutar ulivnog sistema su doveli do efikasnog smanjenja brzine strujanja liva.

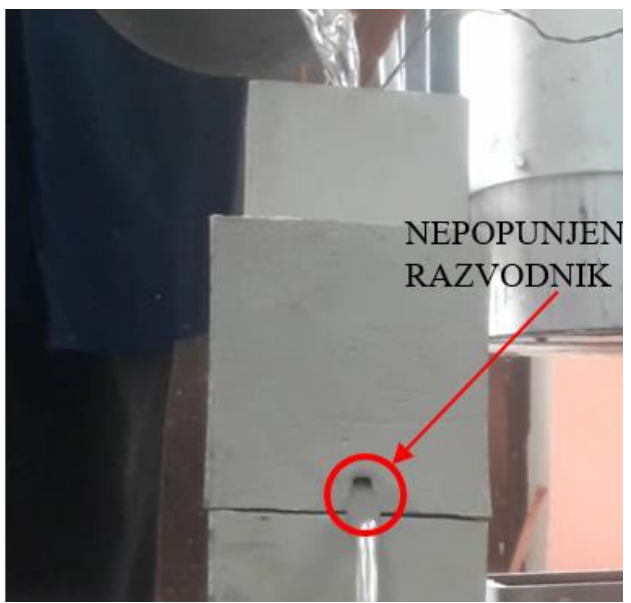

Slika 8. Isticanje rastopa iz ravnog povišenog razvodnika

Analizom snimaka struje tečnog metala snimljenih $u$ pravcu isticanja, uočeno je da povišeni razvodnici na izlazu nisu bili potpuno ispunjeni tečnim metalom, slika 8. Ovo je dovelo zahvatanja vazduha u razvodniku i povremenog prekida struje metala, čime je precizno očitavanje brzina strujanja bilo otežano. Za očekivati je da bi ovako dobijena struja tečnog metala izmešana sa vazduhom dovela do nižih mehaničkih osobina odlivka. Stoga se ne preporučuje upotreba povišenih razvodnika, već je neophodno proračunati tačnu geometriju istih, uzimajući u obzir eksperimentalno utvrđen koeficijent isticanja od 0,55. Treba napomenuti da je sličan problem sa zahvatanjem vazduha primećen i kod krivudavog normalnog razvodnika koji je na izlazu bio potpuno ispunjen livom. Pretpostavlja se da je uzrok ovoj pojavi loš spoj na podeonoj ravni i mogućnost zahvatanja vazduha u zonama potpritiska u unutrašnjoj zoni krivine.

\section{ZAKLJUČCI}

[1] Razvijena eksperimentalna postavka je adekvatna i može se koristiti za određivanje brzina strujanja rastopa na izlasku iz razvodnika ili ulivnih kanala.

[2] Kako bi se smanjio uticaj varijacije nivoa liva u ulivnoj čaši, a u cilju dodatnog povećavanja preciznosti merenja, u budućim istraživanjima se preporučuje primena ulivne čaše sa prelivnim kanalom.

[3] Dobijeni rezultati pokazuju da je koeficijent isticanja liva kod manjih i jednostavnih ulivnih sistema niži od trenutno preporučenih 0,8. Primena navedenog koeficijenta isticanja pri proračunu ulivnog sistema dovodi do nedovoljnog iskorišćavanja svih energetskih gubitaka prisutnih u ulivnom sistemu.

[4] Dodavanjem krivina u okviru razvodnika moguće je postići dodatno usporavanje liva. Međutim, u okviru ovog istraživanja primena krivudavih razvodnika izazvala je povećano zahvatanje gasova.

\section{LITERATURA}

[1] J. Campbell, “ Complete Casting Handbook: Metal Casting Processes, Metallurgy, Techniques and Design”, Oxford, Elsevier Butterworth-Heinemann, 2015.

[2] L. Kovačević, "Savremene tehnologije livenja skripta", Novi Sad, Fakultet tehničkih nauka, 2018.

[3] R. Kovač, "Tehnologija izrade odlivaka", Novi Sad, Fakultet tehničkih nauka, 2006.

[4] P. Beeley, "Foundry technology", Oxford, Elsevier Butterworth-Heinemann, 2001.

[5] J. Campbell, "Castings Practice: The Ten Rules of Castings", Oxford, Elsevier Butterworth-Heinemann, 2004.

[6] I. Galić, I. Katavić, I. Kerekeš, J. Pirš, “Ljevački priručnik”, Zagreb, Savez ljevača Hrvatske, 1985.

[7] F.-Y. Hsu, M. R. Jolly, J. Campbell, “ A multiple-gate runner system for gravity casting", Journal of Materials Processing Technology, Vol. 209, pp. 57362750, 2009.

\section{Kratka biografija:}

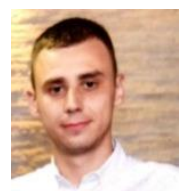

Slaviša Trifunović rođen je u Loznici 1995. godine. Diplomirao je 2018. godine na Fakultetu tehničkih nauka u Novom Sadu iz oblasti mašinskog inženjerstva - studijski program Proizvodno mašinstvo. kontakt: zeko.trifunovic@gmail.com

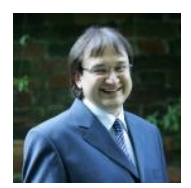

Lazar Kovačević rođen je u Beogradu 1981. godine. Doktorirao je na Fakultetu tehničkih nauka 2015. god., gde od 2016. godine radi u zvanju docenta. 